\title{
Genealogia como exercício de contramemória: Afrânio Peixoto e a emergência da escola (1932-1942)
}

\author{
Genealogy as a contramory exercise: \\ Afranio Peixoto and the emergence of the school (1932-1942) \\ La genealogía como un ejercicio de contramemoria: \\ Afranio Peixoto y la emergencia de la escuela (1932-1942) \\ José Gonçalves Gondra \\ Universidade do Estado do Rio de Janeiro (Brasil) \\ Bolsista de Produtividade em Pesquisa do CNPq; Pesquisador da Faperj \\ http://lattes.cnpq.br/6103523487830536 \\ http://orcid.org/0000-0002-0669-1661 \\ gondra.uerj@gmail.com
}

\section{Resumo}

Neste artigo, exploro alguns princípios narrativos contidos no manual Noções de História da Educação, objeto de três reedições sucessivas (1933, 1936 e 1942), de autoria do polígrafo, Afrânio Peixoto, resultante dos três anos de sua vida (1932-1934) dedicados ao ensino de história da educação no Instituto de Educação do Rio de Janeiro. Nesta narrativa, Peixoto oferece às futuras professoras aquilo que designa como uma "história da civilização", capital considerado necessário para que compreendessem a "ponta extrema do passado" e outros presentes, condição para se obter uma maior profissionalização da docência. Com este investimento, trabalho no registro de uma espécie de origem da escola, de fundação primeira, operando com marcos fundamentais destinados a comprovar a substância e funções deste acontecimento. No presente exercício, procuro desfazer a perpetuação imóvel de uma suposta identidade e funcionamento da escola, suspensa no tempo, para tentar pensar nas operações historiográficas e movimento pedagógico aos quais o referido manual se filia e que ajuda a legitimar e reproduzir.

Palavras-chave: Afrânio Peixoto. Noções de História da Educação. Historiografia da Educação Brasileira. 


\begin{abstract}
In this article, I explore some of the narrative principles contained in the book Notions of History of Education, object of three successive reissues (1933, 1936 and 1942), by the polygraph, Afrânio Peixoto, resulting from the three years of his life (1932-1934) to the (,) teaching of history of education at the Institute of Education of Rio de Janeiro. In this narrative, Peixoto offers future teachers what he calls "a history of civilization", capital considered necessary for them to understand the "extreme tip of the past" and other present times, a condition to obtain a greater professionalization of teaching. With this investment, the author works in the registry of a type of school origin, of first foundation, operating with fundamental milestones to prove the substance and functions of this event. In the present exercise, I seek to undo the immovable perpetuation of a supposed school identity and its operation, suspended in time, to try to think about the production process and the historiographic operations and pedagogical movement to which the cited manual joins, which helps to legitimize and reproduce.
\end{abstract}

Keywords: Afrânio Peixoto. Notions of History of Education. Historiography of Brazilian Education.

\title{
Resumen
}

En este artículo, exploro algunos de los principios narrativos contenidos en el manual Nociones de Historia de la Educación, objeto de tres ediciones sucesivas (1933, 1936 y 1942), escritas por el polígrafo Afrânio Peixoto y resultado de los tres años de su vida (19321934) dedicados a la enseñanza de la historia de la educación en el Instituto de Educación de Río de Janeiro. En esta narrativa, Peixoto ofrece a los futuros maestros lo que el denomina como una "historia de la civilización", la que consideraba necesaria para que comprendiesen la "punta extrema del pasado" y de otros presentes, como una condición para conseguir una mayor profesionalización de la docencia. Con este empleo, el autor trabaja en el registro de una especie de origen de la escuela, de primera fundación, operando con marcos fundamentales destinados a probar la sustancia y funciones de ese evento. En el presente ejercicio, trato de deshacer la perpetuación inmóvil de una supuesta identidad y funcionamiento de la escuela suspendida en el tiempo para tratar de pensar en las operaciones historiográficas y el movimiento pedagógico al que se encuentra afiliado este manual y que ayuda a legitimar y reproducir.

Palabras clave: Afrânio Peixoto. Nociones de Historia de la Educación. Historiografía de la Educación Brasileña. 
Sempre impetuoso, sempre arrojado, sempre total em suas campanhas. (...) [Afranio Peixoto] era um mestre, um amigo, um animador, um escritor, um conversador incomparável, um irradiador de cultura, um centro de convergência que seduzia, que agitava tudo e todos em torno de si. (...) Fascinou sempre a mocidade e conservou uma mocidade de espírito que jamais o traiu até morrer.

Athayde in Ribeiro, 1950, p. XV

\section{Introdução}

Ao apresentar o livro de Leonídio Ribeiro, Tristão de Athayde descreve Afrânio Peixoto como extraordinário polígrafo, homem polimorfo, conquistador impertinente e competente, perito, de inteligência dúctil, vontade de ferro, curiosidade incansável e de inventividade inesgotável, tom encomiástico esperado para uma biografia redigida por um ex-aluno do biografado.

Peixoto efetivamente atuou em múltiplas funções ao longo de sua trajetória, sem que seja possível aquilatar as inúmeras qualidades destacadas na epígrafe, o que não se constitui em foco deste artigo. O desafio aqui é de outra ordem.

Como médico, foi professor de higiene, medicina legal e criminologia; atuando,

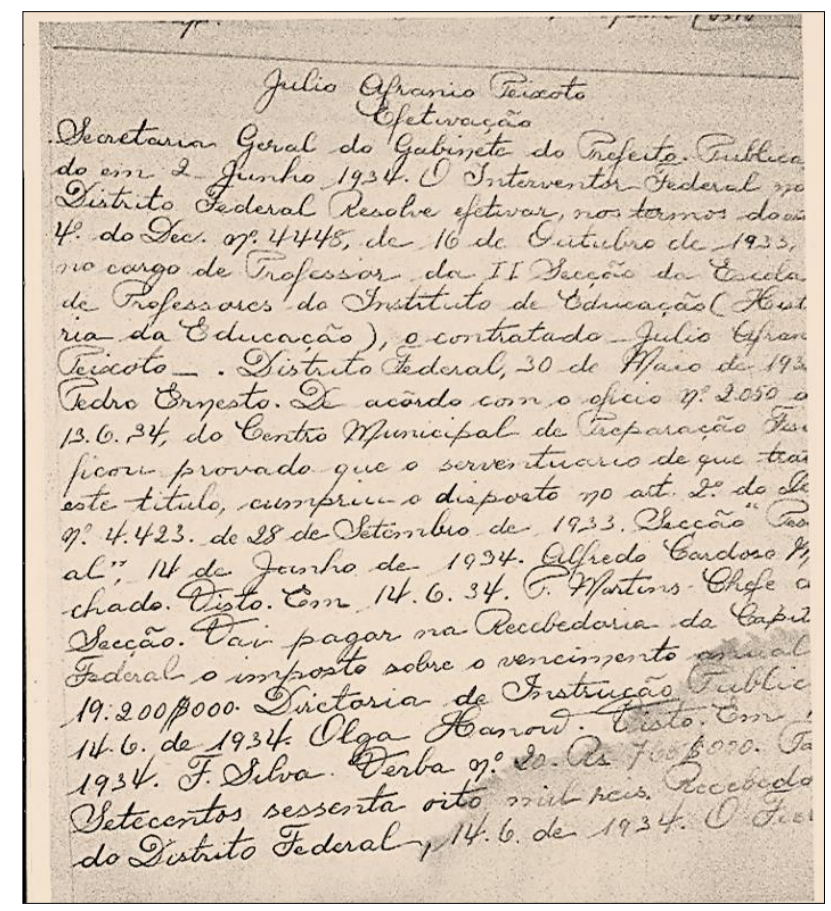

Figura 1 - Termo de Efetivação - Livro de designação do Instituto de Educação do Rio de Janeiro (1934) igualmente, no parlamento, na administração pública e nos campos literário e da história ${ }^{1}$. Durante três anos de sua vida (1932-1934), ensinou história da educação no Instituto de Educação do Rio de Janeiro (IERJ). Desta experiência resultou o livro Noções de História da Educação, objeto de três reedições sucessivas (1933, 1936 e 1942) $)^{2}$, no qual sistematiza o curso "ditado" e produz uma memória do que deveria ser ensinado às futuras professoras da capital ${ }^{3}$. Neste cursolivro, estabelece uma origem para a escola, postulando, igualmente, uma determinada função para o dispositivo escolar, a ser reproduzida na e pela própria instituição de formação de professoras. No exercício aqui realizado, procuro estabelecer uma contramemória deste acontecimento, procurando dissipar este começo, atento para as descontinuidades que atravessam a

\footnotetext{
${ }^{1}$ A respeito da trajetória de Peixoto, cf. a sua biografia escrita por um de seus discípulos na Faculdade de Medicina do Rio de Janeiro: Ribeiro, 1950.

${ }^{2}$ Este texto é desdobramento de investimentos prévios e de outras focalizações da produção de Peixoto. A este respeito cf. Gondra, J. \& Silva. J (2011 e 2011a); Gondra, J. \& Sily, P. (2012 e 2013) e Gondra, 2011.

${ }^{3}$ Livro que, segundo o autor, teria sido inspirado em dois manuais "dignos de cópia", os livros de Paul Monroe (1907 e 1939) e Stephen Duggan (1916). A respeito do manual de Monroe, cf. Silva; Favaro, 2014.
} 
emergência e funcionamento da escola, bem como dos saberes e agentes associados ao dispositivo escolar.

\section{O curso-livro}

No início do relatório sobre a disciplina, publicado em 1935, na revista do Instituto de Educação, Afrânio Peixoto oferece alguns elementos que ajudam a pensar a execução do programa nas turmas 11,12 e 13 sob sua responsa-bilidade ${ }^{4}$.

Para ele, o processo de ensino de história da educação só poderia ser o informativo associado ao debate ou seminário, pois se tratava de um saber que não comportava a possibilidade de experimentação. Em seguida, oferece dois testemunhos pessoais; dos cursos de 1933 e 1934.

Em 1933, as alunas escolheram um educador ou um sistema de educação. Já em 1934, os

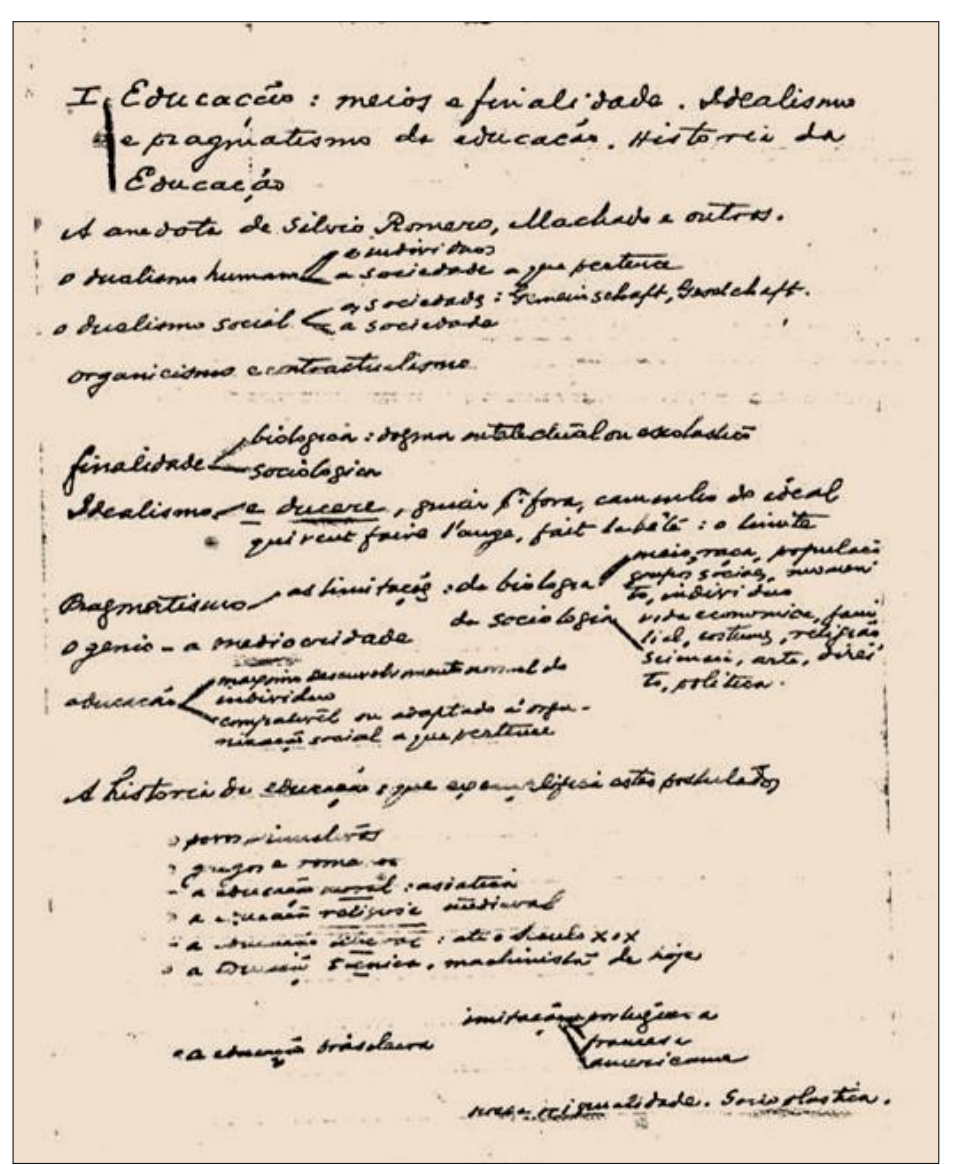

Figura 2- Anotações do curso de História da Educação do IERJ Acervo Casa de Cultura Afrânio Peixoto. assuntos foram sorteados para evitar que "a simpatia levasse muitas delas ao mesmo tema".

Ao lado deste trabalho, as alunas leram "Emilio", de J. J. Rousseau. De acordo com o relato, o livro foi discutido, a pedagogia de Rousseau foi criticada, Sabido seu ambiente histórico, seus precursores e seus contemporâneos, ideias alheias e próprias e, principalmente, seu êxito e condenação.

Embora contido no manual, o relatório publicado na revista oficial do IERJ dá a ver estratégias complementares adotadas pelo professor, como a prática do seminário e os deslocamentos operados no exercício da disciplina ${ }^{5}$.

Uma pista complementar, que permite tomar distância da tese do livro como "observatório das aulas" (Gondra \& Teixeira, 2010), consiste nas notas do curso, depositadas na Casa de Cultura Afrânio Peixoto ${ }^{6}$, na cidade natal do autor, em Lençóis, Bahia. Este documento recobre pontos ausentes do livro, indício de que se o livro deveria funcionar como "o grande mestre das escolas" (Teixeira, 2008), o autor mesmo não converteu o livro em um espelho das aulas ditadas para as alunas do IERJ, ainda que do ponto de vista doutrinário seja possível perceber homologias entre as anotações

\footnotetext{
${ }^{4}$ Cf. Termo de Designação de Afrânio Peixoto para a Escola de Educação do IERJ, assinado por Lourenço Filho em 14 de agosto 1936.

${ }^{5}$ Um exercício adicional consistiria em entrecruzar estas fontes com o programa oficial da disciplina, composto por 33 pontos, investimento não realizado neste texto.

6 Disponível em http://www.cultura.ba.gov.br/2015/12/555/Casa-de-Cultura-Afranio-Peixoto-comemoraaniversarios-este-mes-em-Lencois-.html. Acesso em 31 jan. 2019.
} 
manuscritas e o manual publicado logo depois do primeiro curso que ministrara para as normalistas do IERJ, em 1932.

Nas notas e no livro, os princípios assumidos desde o prefácio da primeira edição ganham visibilidade quando afirma que a "globalização da cultura mal suportava o artifício indidático, das monografias especializadas". Para ele, tratava-se de um tipo de instrumento que, talvez, pudesse ser instrutivo, mas certamente não era educativo por serem "inapetentes e fatigantes". Com isto, o homem de letras, ciência, história, do parlamento, da gestão, educação e do ensino argumenta em favor do que ensina e escreve, isto é, uma perspectiva panorâmica não redutível ao que descreve como "campos microscópicos meramente documentais". O curso, portanto, estava comprometido e alinhado a uma finalidade educacional, flagrando a evolução de algumas ideias, menos preso à cronologia de fatos, datas e nomes. Ao prefaciar o manual nestes termos, o autor reconhece e colabora para delinear contornos para as diretrizes da disciplina, acoplados a uma determinada concepção de formação, projeto institucional de renovação pedagógica e perspectiva da ação social das normalistas ${ }^{7}$.

Se há, do ponto de vista doutrinário, uma espécie de linha forte de interconexão entre curso e livro ${ }^{8}$, do ponto de vista do arranjo das aulas "ditadas" e daquelas a serem guiadas pelo manual, há traços de opacidade e diferenciações, como se pode conferir na tabela $1^{10}$.

Tabela 1- Comparativo entre Sumário "Noções" e "Anotações” para as aulas de História da Educação

\begin{tabular}{|c|c|}
\hline Sumário & Anotações para as aulas \\
\hline Prefácio & \\
\hline $\begin{array}{l}\text { I- Introdução } \\
\text { Selvagens e Primitivos } \\
\text { Gênios } \\
\text { Educação para a sociedade }\end{array}$ & $\begin{array}{l}\text { I-Educação - Meios e finalidades. Idealismo e pragmatismo da } \\
\text { educação. História da Educação } \\
\text { A anedota de Silvio Romero, Machado e outros } \\
\text { O dualismo humano: o indivíduo } \\
\quad \text { a sociedade a que pertence } \\
\begin{array}{l}\text { Dualismo social } \\
\text { - Organicismo e contratualismo }\end{array}\end{array}$ \\
\hline $\begin{array}{l}\text { II- Educação arcaica } \\
\text {.. Sincronismo } \\
\text {..India } \\
\text {..China } \\
\text { Caldeia-Assíria } \\
\text {..Pérsia) }\end{array}$ & $\begin{array}{l}\text { II-Povos primitivos e selvagens: educação rudimentar, } \\
\text { interesses imediatos de sobrevivência. Mentalidade mística e } \\
\text { pré-lógica. } \\
\text { Resumo anterior: o gênio e a mediocridade - indivíduo e } \\
\text { sociedade. } \\
\text { O selvagem - o mito do bom selvagem... até Rousseau } \\
\quad \text { - antes Montaigne.. Brasil.. depois Romantismo } \\
\quad \text { - a realidade: Hobbes, Freud }\end{array}$ \\
\hline
\end{tabular}

\footnotetext{
${ }^{7}$ Peixoto constrói um texto folheado, marcado pela erudição, recorrendo a ferramentas distintas de legitimação de seu discurso. Apoiado em uma lista variada de autores, textos, personagens, reforça sua palavra apoiado em um jogo de rebatimento múltiplo a 326 autores/personagens. O volume das referências como medida de legitimação é reforçado pelo emprego mais ou menos regular do latim e do francês, ao lado das notas de pé de página e do recurso à ilustração. No capítulo relativo à Escola Nova, chama atenção a fotografia coletiva, a única que ocupa página inteira, na qual aparecem "os pioneiros da escola nova", como consta na descrição da mesma, que são: Ovide Décroly, Pierre Bovet, Bernard Ensor, Edouard Claparède, Paul Geheeb e Adolphe Ferrière. (1946, p. 334).

${ }^{8} \mathrm{O}$ livro Noções de História da Educação nasceu da contingência das aulas, como alguns dos livros de Afranio Peixoto. Dentre eles, podemos citar o Medicina Legal (com nove edições até 1946), Psico-patologia forense (com seis edições até 1935), Noções de higiene (com oito edições até 1941), Elementos de higiene (com seis edições até 1936). No caso do Noções de história da educação, ele também pode ser lido sob o registro de "transunto e memória".

${ }^{9}$ As "Anotações" relativas às aulas constituem um documento de vinte páginas, manuscrito. O original pode ser encontrado na Casa de Cultura Afrânio Peixoto, na cidade natal do autor.

${ }^{10}$ Para evitar saturação, do total de 20 capítulos da primeira edição (1933), trabalhei com os dois capítulos iniciais e com o capítulo dedicado ao Brasil, procurando correspondência nas "Anotações" consultadas.
} 


\begin{tabular}{|c|c|}
\hline & 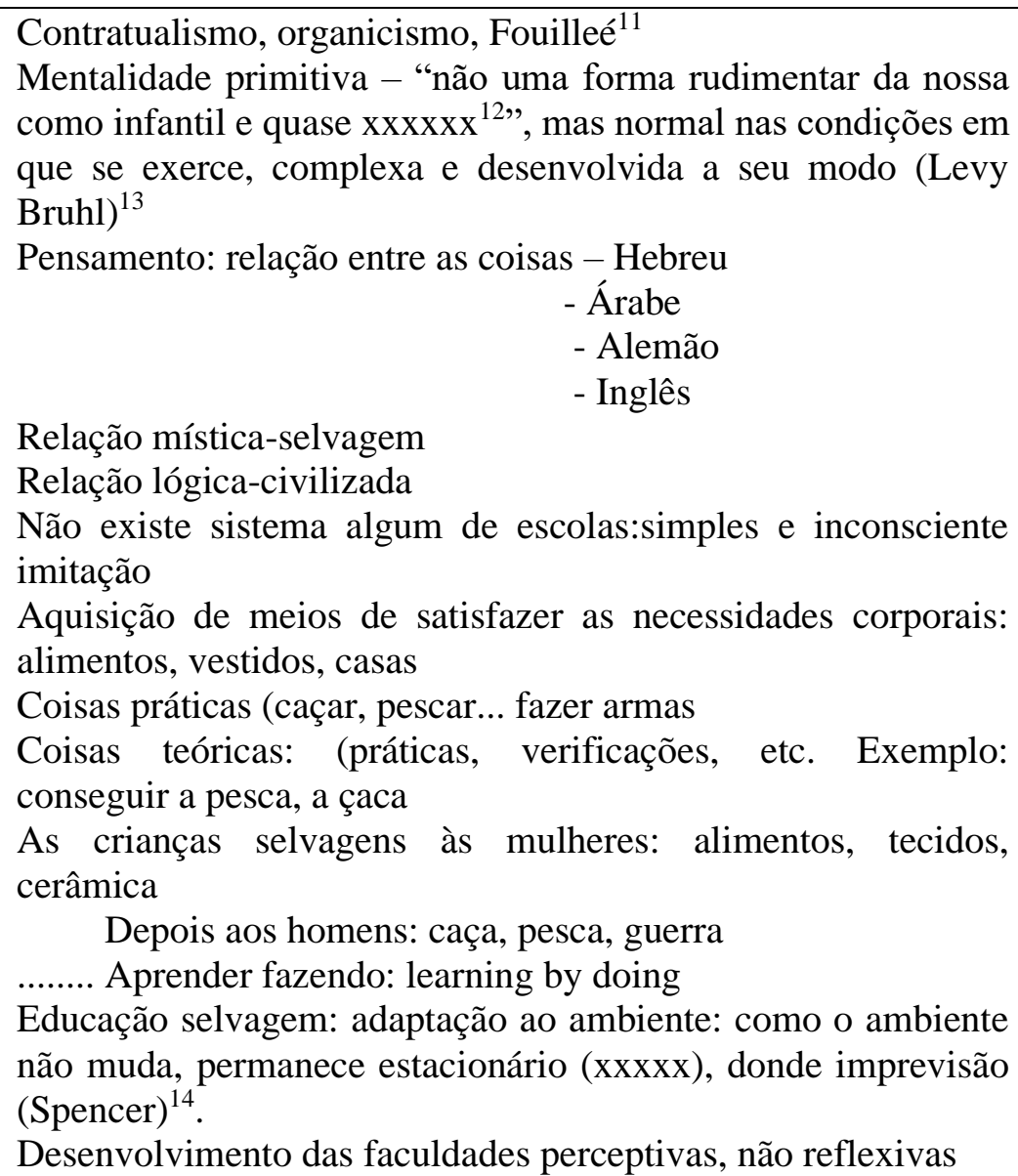 \\
\hline $\begin{array}{l}\text { XVII, XVIII e XIX - Brasil }{ }^{15} \\
\text {..Sincronismo } \\
\text {..Brasil } \\
\text {..Jesuítas: Anchieta } \\
\text {..Pombal; "subsídio literário" } \\
\text {..Monarquia (1822-1889) } \\
\text {..República (1889-1932) }\end{array}$ & $\begin{array}{l}\text { XXVI'16 - Educadores brasileiros - Precursores: jesuítas, } \\
\text { Anchieta } \\
\text { Ferreira França } \\
\text { Lino Coutinho e as Cartas à Cora } \\
\text { Pero II. Tautphoeus, Calógeras, Ramiz Galvão } \\
\text { Bernardo Pereira de Vasconcelos e o ensino secundário } \\
\text { Abilio Borges - nascido em Rio das Contas, onde estudou }\end{array}$ \\
\hline
\end{tabular}

11 Alfred Jules Émile Fouillée (1838 - 1912) foi um filósofo francês, autor de diversas obras no campo da sociologia, psicologia e algumas categorias e autores da filosofia, tais como moral, metafísica, caráter, Nietzsche e Kant. Alguns livros deste autor se encontram disponíveis em https://archive.org/. Acesso em 4 fev. 2018.

12 Palavra incompreensível no manuscrito original. Há outras situações semelhantes na leitura deste documento, assinaladas com o mesmo padrão: xxxxxx.

13 Filósofo, antropólogo e sociólogo francês, Lucien Lévy-Brühl (1857-1939), pertenceu à geração republicana de acadêmicos franceses, fortemente marcada pela filosofia positivista e pelos ideais da democracia laica. Formado pela École Normale Supérieure, foi professor de Filosofia na Sorbonne entre 1899 e 1927. A sua obra reflete o positivismo de Auguste Comte e adota o conceito de representação coletiva do sociólogo Émile Durkheim. O seu livro La Morale et la Science des Moeurs (1903) constituiu uma base de referência para uma sociologia relativista. Os seus estudos dirigiram-se majoritariamente para a análise da mentalidade dos povos das chamadas sociedade primitivas. Segundo Lévy-Brühl, o pensamento destes povos está imbuído de misticismo e não é governado exclusivamente pelas leis da lógica, o que o distinguiria do raciocínio das sociedades modernas ocidentais. A respeito deste autor, cf. Tambiah, 2013.

${ }^{14}$ A respeito deste autor, cf. Pinheiro, Sily \& Gondra, 2019.

${ }^{15} \mathrm{O}$ tema do Brasil aparece agrupado em três capítulos.

16 Uma nota a respeito das correspondências entre as "Anotações" e o Sumário do livro. Não há correspondência direta, cabendo sublinhar que a existência de falhas na numeração das notas. Um exemplo, do item VI passa-se para o item IX. Há igualmente uma diferença no número de itens. O livro contém 20 capítulos, já as "Anotações" encerram no item XXVIII, intitulado "A lição do passado". 


\begin{tabular}{|l|l|}
\hline. .Educadores Brasileiros & latim, francês e filosofia. O Atheneu - Raul Pompeia. \\
$.1847-$ Médico; 1856 - diretor do xxxx \\
$.1857-400$ anos no sertão e 600 dos xxxx. Método (xxxx \\
silabação contra soletração. Ensino progressivo, assim direto \\
das línguas, depois gramática, xxxx, ciências, coeducação dos \\
sexos, contra os exames de satã, matemática escolar \\
Medeiros de Albuquerque e o Pedagogium ${ }^{17}$ \\
Benjamim Constant e a Escola Normal e Benjamin Constant \\
ministro \\
Ruy Barbosa e o relatório de 1882 \\
As reformas da República \\
Cesário Mota em São Paulo, prédios escolares. \\
Azevedo Sodré e ensino profissional. Escola Normal \\
noturna. Limite de matrículas. \\
Frontin e os quatro excessivos: Anísio Teixeira \\
Veríssimo e seu livro \\
Góes Calmon e Anísio Teixeira na Bahia \\
Francisco Campos em Minas \\
Fernando de Azevedo e a escola ativa \\
Anísio Teixeira e Lourenço Filho e xxxxx \\
Educação da mulher \\
Educação dos rapazes \\
Educação profissional superior \\
Universidade. Escola Normal Superior. Faculdade de Filosofia \\
e xxxx \\
Marta e Maria \\
\end{tabular}

Nota: Organização do autor

A partir do comparativo entre o livro e as anotações de aula cabem três comentários. O primeiro diz respeito às remissões tópicas ao período colonial, com um conjunto de destaques importantes ao período do Império e um acento, ainda mais forte, ao que se processa no período republicano, sobretudo ao que é contemporâneo ao autor. No que se refere aos contemporâneos do autor cabe destacar a presença do conterrâneo Anísio Teixeira e dos protagonistas do movimento da escola nova, iniciando-se com Azevedo Sodré, até Fernando de Azevedo. Outro aspecto a ser observado se refere a presença de algumas temáticas. Neste caso, vale retornar a referência ao baiano do século XIX, Abílio Cesar Borges e da agenda a que o mesmo é vinculado, isto é, a renovação da escola e dos métodos; o que ajuda a compreender o destaque colega de ofício e conterrâneo, igualmente poliédrico ${ }^{18}$. Por fim um destaque via contraste diz respeito à ausência de protagonistas femininas no sincronismo e nas notas de aula relativo ao Brasil, ainda que nas "Anotações" demonstre preocupação com a educação da mulher. No entanto, o sistema de referência e os argumentos de autoridade mobilizados pelo autor são todos masculinos.

\footnotetext{
${ }^{17}$ Há uma seta nas "Anotações", indicando que este tema deveria ser abordado depois do item "As reformas da República", indício complementar com de sua adoção do cronológico como princípio estruturante da narrativa, do ensino e da história.

${ }^{18}$ A respeito deste autor, cf. Gondra, 2002.
} 


\section{Um livro lateral}

No poliedrismo e vastidão da produção escrita do médico baiano, Noções de História da Educação se constitui em uma produção secundária. No entanto, instalada nos domínios da história da educação passa a ocupar outra posição, menos por ser considerado o primeiro manual destinado ao ensino de história da educação em cursos de formação de professores, destacadamente no IERJ e nas escolas normais. O acento e relevo deste enunciado decorrem do mesmo se inscrever em determinada cadeia discursiva, comprometida com a reforma da sociedade por intermédio da renovação da escola, articulada à concepção de história como "mestra da vida", a partir da qual o passado é convertido em fonte de lições a serem seguidas, mas também abandonadas. Nesta chave, procura estabelecer uma relação íntima entre a ação virtuosa, isto é, uma ação guiada pela ponderação e reflexão, e os exemplos do passado.

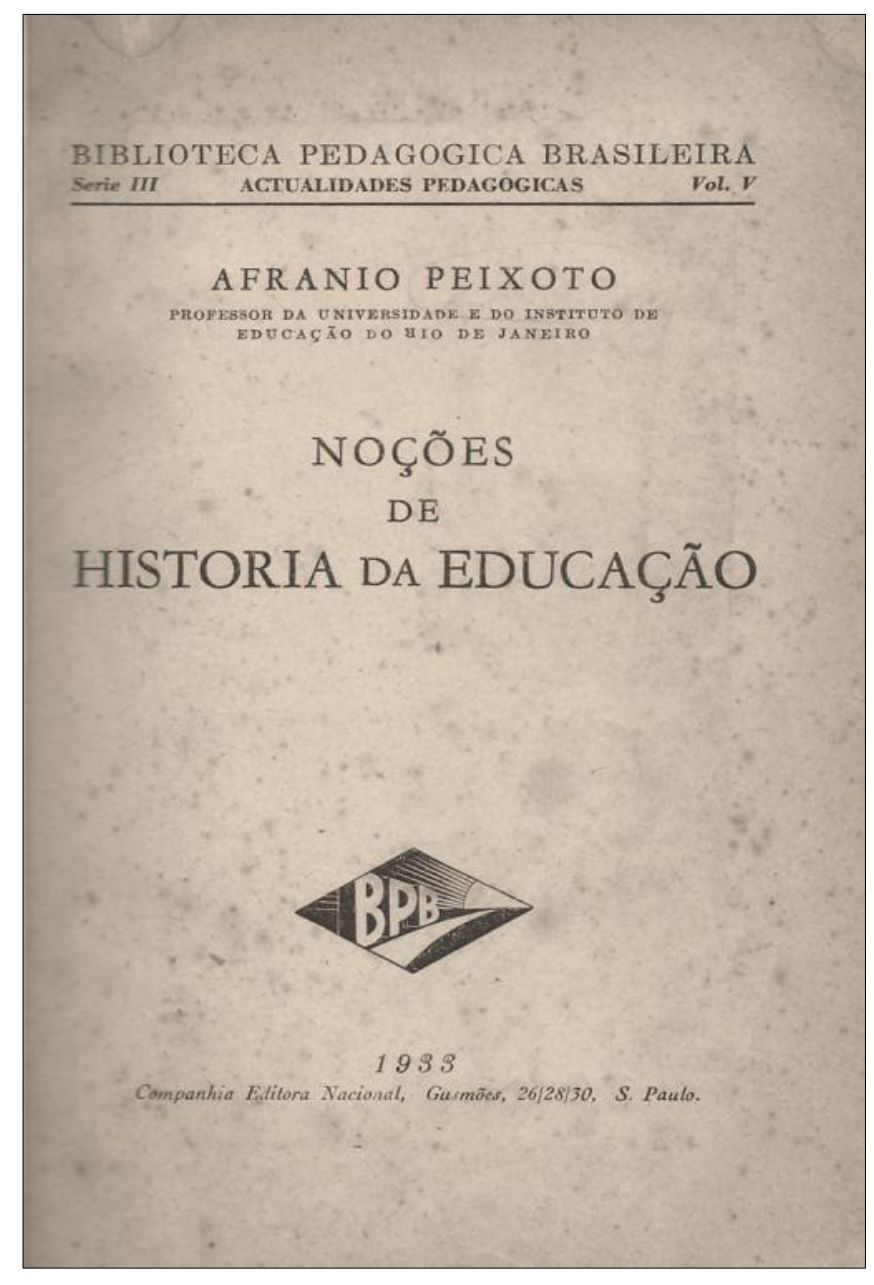

Figura 3- Capa do livro Noções de História da Educação $1^{\mathrm{a}}$ edição, 1933.
Assim, a história, como engrenagem responsável por gerir os acontecimentos passados deveria ser considerada "mestra da vida", isto é, por meio dos exemplos e contra-exemplos, a história da educação deveria ensinar às futuras professores a agirem de forma melhor e com mais prudência. Adere, portanto, à concepção da história que deveria funcionar como fundamento moral para as novas condutas.

No que se refere aos modelos narrativos, o autor instaura uma polaridade interessada, ao distinguir o monográfico do panorâmico, destacando os benefícios desta última solução para o público a que o livro se destina e de cuja experiência resulta; como assinalado. $\mathrm{Na}$ exploração desta narrativa, focalizei $\mathrm{o}$ modo como Peixoto se refere ao aparecimento da escola, procurando problematizar o enunciado contido no livro, com base nas postulações de Foucault a respeito da história e da genealogia.

De acordo com Resende (2005), a pesquisa genealógica permite $\mathrm{o}$ reencontro do múltiplo nos acontecimentos tomados como único, como se sua formação tivesse ocorrido
ca com que trabalhei, alinhado à síntese de de maneira ímpar, contínua, sem dispersões ${ }^{19}$. A ótica com que trabalhei, alinhado à síntese de Resende (2005, ibidem), busca considerar a dispersão peculiar aos acontecimentos, a presença mais ou menos regular dos acidentes, fissuras, enganos, falhas, errâncias que configuram as existências/experiências. Nesta linha, não se trata, pois, de se promover um recuo no tempo para o restabelecimento de uma continuidade evolutiva prolongada até o presente, considerando-o como parte de uma longa e inevitável cadeia de causalidades, desprezando-se

\footnotetext{
${ }^{19}$ On the genealogy, cf. Medina, 2011 and Tamboukou, 1999.
} 
as exterioridades acidentais. Acompanhando estas advertências, procuro observar a presença da escola na narrativa articulada aos jogos de regulação, nos quais se pode pensar a palavra como acontecimento, uma vez que resultam e integram determinadas conformações e demarcação de posições; investindo-se no que se deseja legitimar, enfraquecer e recompor a partir das forças em relação. Para Foucault, uma história elaborada nestes marcos seria uma história efetiva, pois

A história genealogicamente dirigida não tem por fim reencontrar as raízes de nossa identidade, mas ao contrário, se obstina em dissipá-la; ela não pretende demarcar o território único de onde nós viemos, essa primeira pátria à qual os metafísicos prometem que nós retornaremos, ela pretende fazer aparecer todas as descontinuidades que nos atravessam (Foucault, 1992)

Ao acompanhar esta linha de reflexão, trata-se de perceber, na narrativa destinada às professoras, a encenação construída pelo autor, com base nas operações realizadas, considerando as condições de produção deste enunciado, os agenciamentos dos quais o autor participava, bem como a gramática disponível à época em temos do fazer história e história da educação.

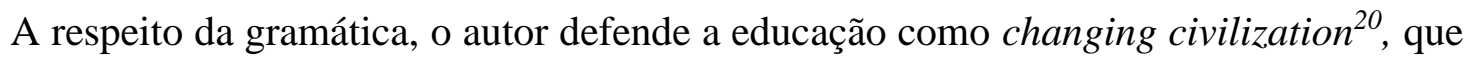
olha o futuro preocupada, tentando aperfeiçoar os "órgãos desse imenso e imortal organismo, que é a sociedade". No interior desta verdade, o futuro humano "só pode ser resolvido com a experiência anterior do passado"; o que considera como justificativa educativa e pedagógica, para o estudo "dessa história da educação". Nesta chave, um duplo posicionamento. O primeiro a respeito da educação definida como civilização em marcha, do passado para o futuro. O segundo corresponde a uma definição da história e de seu caráter liceal e pragmático; ambos associados aos referenciais daquilo que designa por "escola ativa", grande parte inspirada no que se passa em partes da Europa e nos Estados Unidos. Para ele, os americanos no Norte não esperaram o milagre pré-lógico, tampouco os remédios místicos: "tratam de resolver o problema, como na escola ativa, com a experiência anterior, logicamente...” (1933, p. 11). Fixa, assim, uma dupla formulação acoplando-as a um modelo a ser seguido, bem como experiências contra exemplares, selvagens, irracionais, não científicas.

A longa e inevitável marcha para o futuro pode ser evidenciada em um dos elementos regulares do manual, o sincronismo, organizador da narrativa, presente do segundo ao vigésimo capítulo. Este recurso funciona como uma espécie de linha do tempo, iniciada no ano 5000 antes de cristo (a.c.), encerrando-se no presente do autor, no capítulo especialmente dedicado à Escola Nova. O extenso intervalo funciona como mecanismo para o autor dar visibilidade aos acontecimentos considerados mais relevantes para se compreender a marcha civilizatória, ressaltando aqueles que estariam mais relacionados com a história da educação e com a renovação do ensino. Para efeitos desta reflexão, focalizei as remissões ao termo escola $^{21}$ inscritos nos 6.932 anos recobertos pela narrativa, como recurso que permite reconhecer a presença deste referente nos sincronismos organizados pelo professor-autor ${ }^{22}$.

\footnotetext{
${ }^{20}$ Expressão empregada pelo autor, no original.

${ }^{21}$ Há muitas remissões ao termo Universidade, a partir de 1158, quando assinala a criação da Universidade de Bolonha, o que parece sugerir a existência de um tipo de relação causal entre formação superior e a marcha da civilização. Há, igualmente, a referência a colégios, asilos, jardins de infância e reformas escolares, por exemplo.
} 
A primeira ocorrência do termo escola aparece no ano de 392 a.c., atribuindo à Isócrates o estabelecimento de uma escola em Atenas. As outras remissões podem ser conferidas na tabela 2 .

Tabela 2- Ocorrências do termo escola nos sincronismos de "Noções"

\begin{tabular}{|c|l|}
\hline Ano & \multicolumn{1}{|c|}{ Remissão } \\
\hline 392 a.c. & Isócrates estabelece uma escola em Atenas \\
\hline 75 a.c. & Primeiras escolas subvencionadas pelo Império \\
\hline 529 d.c. & (Justiniano) Abole as escolas pagãs \\
\hline 817 d.c. & Divisão das escolas monásticas em internas e externas \\
\hline 1089 & $\begin{array}{l}\text { São Hugo, abade de Cluny, começa a construção da igreja abacial, protótipo e escola de } \\
\text { arquitetura de romance. }\end{array}$ \\
\hline 1101 & Escola de Salerno \\
\hline 1231 & A escola médica de Salerno privilegiada \\
\hline 1537 & Fundação da escola de Sturm ${ }^{23}$ \\
\hline 1559 & Plano escolar de Wurtemberg ${ }^{24}$ primeiro sistema de escolas públicas \\
\hline 1633 & Primeira escola nos Estados Unidos \\
\hline 1794 & Escola normal na França \\
\hline 1633 & Primeira escola em "Nova Amsterdam", depois Nova York \\
\hline 1635 & Escola latina de Boston \\
\hline 1805 & Sociedade em favor da escola pública, em Nova York. \\
\hline 1821 & Primeira escola superior em Boston \\
\hline 1827 & Gratuidade das escolas no Massachussets \\
\hline 1837 & Primeiro superintendente de escolas urbanas \\
\hline 1838 & Primeira escola normal nos Estados Unidos \\
\hline 1845 & Horace Mann, eleito governador de seu Estado, prefere ser diretor de uma escola. \\
\hline 1867 & Gratuidade das escolas públicas em Nova York \\
\hline 1823 & Reforma da instrução primária: introdução do sistema lancasteriano nas escolas públicas \\
\hline 1826 & Lei que mandava abrir escolas públicas primárias nas principais vilas e cidades do Império. \\
\hline 1830 & Escola Normal de Niteroi (Niterói) \\
\hline 1872 & Primeira escola municipal, à praça 11 de junho \\
\hline 1876 & Fundação da Escola de Minas de Ouro Preto \\
\hline 1880 & Escola Normal do Município da Corte, posterior a diversas do país. \\
\hline 1932 & "Manifesto Educacional”: pela escola leiga, obrigatória, única, ativa e progressiva. \\
\hline 1889 & Instituto de Educação \\
\hline 1892 & Escola de Abbotsholme ${ }^{25}:$ Reddie \\
\hline & \\
\hline
\end{tabular}

A exploração de um vocabulário ampliado permite evidenciar a expansão e complexidade do aparato escolar, sinalizado, em certa medida, com a seleção e exploração da presença do termo escola.

${ }^{22}$ Optei por trabalhar com as ocorrências em outros idiomas, tal como empregado pelo autor. Neste caso, aparecem referências ao termo escola em alemão e francês.

${ }^{23}$ Johannes Sturm foi um erudito, pedagogo e também fundador da Universidade de Estrasburgo, cujas origens remontam à criação do Ginásio protestante Jean-Sturm, fundado por ele em 22 de Março de 1538, que dirigiu por 43 anos. Disponível em: _http://words.fromoldbooks.org/Chalmers-Biography/s/sturmius-john.html Acesso em 4 de fevereiro de 2019.

${ }^{24}$ De acordo com Rothbard (2013), o primeiro sistema obrigatório estatal foi estabelecido em 1559 pelo duque Cristopher, príncipe-eleitor de Würtemberg. A frequência era obrigatória, era anotada e os faltosos multados; exemplo logo seguido por outros estados germânicos.

${ }^{25}$ A escola de Abbotsholme foi fundada pelo acadêmico e educador escocês Cecil Reddie, como uma experiência de filosofias e teorias educacionais progressistas. A escola, então conhecida como "The New School", foi aberta para o atendimento de meninos de 10 a 19 anos em 1889. 


\begin{tabular}{|l|l|}
\hline Ano & \multicolumn{1}{|c|}{ Remissão } \\
\hline 1896 & Escola-laboratório da Universidade de Chicago ${ }^{27}:$ J. Dewey \\
\hline 1899 & "École des Roches": ${ }^{28}$ E. Desmoulins. "Bureau International de l'école nouvelle ${ }^{29 "}:$ Ad. Ferrière \\
\hline 1901 & Escolas de Montesca e Rovigliano: Alice Franchetti \\
\hline 1906 & "Project d'école nouvelle": A. Ferrière \\
\hline 1907 & Escola de Ermitage $^{30}:$ O. Decroly \\
\hline 1909 & "Odenwaldschule \\
\hline 1910 & "Arbeitsschule ${ }^{32 ": ~ G . ~ G e h e e b ~}$ \\
\hline 1911 & Métodos Montessori, na escola primária: Maria Guerrieri \\
\hline 1913 & "The schools of to morrow ${ }^{33 ", ~ d e ~ J o h n ~ D e w e y ~}$ \\
\hline 1921 & Escola regional de Merity ${ }^{34}$, de D. Armanda Alvaro Alberto \\
\hline 1926 & Experiências de escola ativa em São Paulo, de Lourenço Filho \\
\hline 1927 & "La paix para l'école", de P. Bovet. "A escola Nova", de Lourenço Filho \\
\hline 1930 & "Introdução ao estudo da escola nova", de Lourenço Filho \\
\hline 1931 & "L'école sur mésure a la mésure du maitre", de Ad. Ferrière \\
\hline 1932 & "Manifesto Educacional" (pela escola nova, ativa, progressiva, com a laicidade, gratuidade, \\
& $\begin{array}{l}\text { obrigatoriedade, co-educação), Rio, São Paulo. Instituto de Educação do Rio de Janeiro, } \\
\text { seminário para a escola progressiva - "Escola moderna", de M. dos Reis Campos. }\end{array}$ \\
\hline
\end{tabular}

Nota: Organização do autor

As 43 ocorrências ao termo escola permitem tecer uma dupla consideração. A primeira, mais evidente, consiste no incremento das remissões a partir do século XIX, com uma curva ascendente até a última ocorrência, associada ao movimento de renovação educacional ao qual o autor se encontrava vinculado e comprometido. Curva que produz efeitos de vinculação causal entre escolarização e a marcha civilizatória. No entanto, não se

${ }^{26}$ A escola foi fundada por Sir William Laxton, originalmente conhecida como "Laxton Grammar School", em 1556. Oundle ganhou destaque como escola inglesa, em grande parte, ao trabalho de F. W. Sanderson como diretor entre 1892 e 1922. Visibilidade que pode ser atribuído ao princípio educacional sustentado por Sanderson, acreditando que se deveria ensinar os alunos o que desejassem aprender.

${ }^{27}$ O primeiro laboratório foi fundado em 1894, inserido na "Graduate School of Education" da Universidade de Chicago, mas só começou a funcionar efetivamente em 1896, concebida como centro de investigação e demonstração de uma nova forma de educar. O laboratório objetivava promover investigação e testar métodos de ensino ativos centrados na criança. Em 1902, a Universidade de Chicago incorporou a "Lab-School" na estrutura universitária, nomeando a mulher de Dewey, Harriet Alice Chipman, como primeira diretora (1902-1904).

${ }^{28}$ A sociedade anônima, "Société de l'École Nouvelle - École des Roches", criada em 1899, adquire o castelo de Roches, há dois quilómetros de Verneuil-sur-Avre. A escola foi inaugurada em 7 de outubro de 1899, quando recebeu 50 alunos, sob a direção de Edmond Demolins (que dirigiu o estabelecimento até sua morte, em 1907), que desejava oferecer um novo tipo de educação, inspirado pelos chamados "métodos ativos", testados nas escolas inglesas de Abbotsholme e Bedales, por ele conhecidos durante viagens de estudo à Inglaterra no início da década de 1890.

${ }^{29}$ A respeito do "Bureau", cf. Hofstetter, 2017.

${ }^{30}$ Em 1907, Ovide Decroly fundou a "École de l'Ermitage”, em Bruxelas, para crianças consideradas "normais". A escola se tornou célebre em toda a Europa, tendo servido de espaço de experimentação para o próprio Decroly. A partir de então, viajou pela Europa e pela América, fazendo contatos com diversos educadores, entre eles o norte-americano John Dewey.

${ }^{31}$ A "Odenwaldschule" consiste em uma escola alemã localizada em Heppenheim no Odenwald, tendo surgida como parte do movimento de reforma educativa, no início do século XX. Foi fundado por Paul Geheeb em 14 de abril de 1910. O pai de Edith Geheeb, membro da câmara municipal de Berlim, Max Cassirer, apoiou a criação do estabelecimento de ensino, financiando a compra de terras e os edifícios. Encerrou as atividades em 2015.

${ }^{32}$ Georg Kerschensteiner foi um educador alemão , professor de matemática e física e fundador da escola que criticava o ensino passivo, defendendo o trabalho como imperativo pedagógico. No início do século XX, as escolas de trabalho encontram-se associadas à pedagogia reformadora alemã e ao projeto de reforma em favor de uma nova escola.

${ }^{33}$ A respeito deste livro do casal Dewey, cf. Sobe, 2017.

${ }^{34}$ A respeito desta escola, cf.: http://portal.inep.gov.br/documents/186968/484184/A+Escola+ Regional+de+ Meriti+\%E2\%80\%93+Document\%C3\%A1rio+1921-1964/3effad90-4b28-4f59-8d9c-d5219e5dcc25?version= 1.0. Acesso em 01 de fevereiro de 2019. 
trata de expandir toda e qualquer escola para as populações, aspecto observável na luminosidade lançada sobre as iniciativas voltadas para a renovação pedagógica, escola progressiva, ativa, nova.

Um segundo comentário incide sobre o destaque atribuído às experiências e autores, compondo uma espécie de roteiro e constituição de um acervo a ser conhecido e consultado pelas normalistas. Acervo que, por sua vez, foi configurado pela proximidade com os princípios doutrinários articulados ao movimento de renovação educacional. Correlativamente, remete aos mundos dignos de serem conhecidos, compondo eixos de comunicação do saber pedagógico, interconectando alemães, suíços, belgas, italianos, ingleses, franceses, estadunidenses e brasileiros.

No caso da remissão aos pares do Brasil, realça dois personagens. O principal corresponde à Lourenço Filho ${ }^{35}$, seja por seu envolvimento com experimentos pedagógicos vinculados à escola ativa, seja pela produção intelectual, demonstrando seu investimento em sistematizar e oferecer ao público um instrumento que permitisse acessar os fundamentos da chamada escola nova. O outro destaque remete a uma experiência de escola renovada, conduzida por Armanda Alvaro Alberto ${ }^{36}$, testemunho adicional das possibilidades de aplicação dos postulados da escola progressiva.

Para refletir a respeito da seleção interessada promovida pelo autor e seus compromissos com alguns princípios doutrinários da renovação da escola, fiz uma incursão mais intensiva no capítulo dedicado ao Brasil, sem desconsiderar o caráter metonímico desta operação. Ainda assim, as oito remissões ao termo escola no capítulo do Brasil remete às preocupações com as reformas com a escola normal, com a criação de escolas municipais, de ensino superior, finalizando com a referência ao chamado manifesto educacional dos pioneiros da educação nova, de 1932, do qual Afrânio Peixoto é um dos signatários.

Com esse tipo de investimento, o médico-professor procura indicar às futuras professoras aquilo que deveria ser efetivamente aprendido, isto é, caberia observar e gravar as ações do Estado, os tipos de estabelecimento constituídos e, sobretudo, os fundamentos que deveriam ancorar um projeto de escolarização científica, o que pode ser observado no lema da escola leiga, obrigatória, única, ativa e progressiva. Marcos estes que estariam sendo postos em prática, no âmbito do Instituto (IERJ), onde a aula estava sendo ministrada, fazendo com que as alunas reconhecessem, no professor e suas aulas, não apenas um relato morno de fatos e datas, mas alguém bastante interessado em difundir e legitimar os princípios da escola nova, condição necessária para que a civilização efetivamente marchasse.

\section{Considerações finais}

Ao evitar uma monografia "inapetente e fatigante", o médico baiano oferece um estudo panorâmico, permitindo às futuras professoras reconhecerem, desde a antiguidade, iniciativas voltadas para a educação e escolarização. Na rígida linha cronológica estabelecida, é possível observar o incremento das remissões ao termo escola, o que se dá de modo fortemente associado às experiências estrangeiras que trilhavam o caminho do progresso, ciência e da civilização. Com este tipo de narrativa, termina por forjar uma linha evolutiva, acoplado a um jogo de causalidades, com base em uma relação de determinação entre escola e civilização.

\footnotetext{
${ }^{35}$ A respeito deste personagem, cf. Monarcha, 2001.

${ }^{36}$ Em fevereiro 1921 fundou a Escola Proletária de Meriti, em Duque de Caxias, atendendo a uma comunidade rural carente. A escola, mais tarde renomeada Escola Regional de Meriti, ficou conhecida como "Mate com Angu", por ter sido uma das primeiras da América Latina a servir merenda escolar. A inovação demonstra a preocupação de Armanda com o bem-estar e a saúde das crianças. A merenda não era a única novidade. Influenciada pelo Método Montessori, uma das derivações da Escola Nova no Brasil. Armanda, diretora, procurou transformar o espaço num laboratório educacional, onde os alunos ficavam na escola no horário integral e ajudavam no cultivo de hortas e criação de animais. A respeito desta experiência, Cf. Mignot (2002) e Moraes (2006).
} 
No entanto, este não se constitui no único recurso presente na narrativa, na medida em que a história ensinada, narrada e a ser reproduzida, também opera no registro da história como "mestra da vida", na história que extrai do passado o que se deveria preservar e aquilo a ser evitado. Trata-se, efetivamente, da história como lição contida na história das "Noções".

Os dois movimentos empregados pelo médico-professor, homens de muitas letras, parece ser derivado dos seus pertencimentos e das militâncias em favor de uma sociedade e da vida regidas por princípios e protocolos da racionalidade científica. Ao circular por campos polimorfos e em processos de configuração, pode testar nas aulas, conferências, ações na gestão pública, na vida parlamentar e na filiação à diversas sociedades científicas a força da razão e a crença na evolução do homem, desde que orientadas pelas racionalidades que o constituíram e que advogou ao longo de sua trajetória poliédrica. Deste modo, em muito sentido, a história da educação evolutiva e como "mestra da vida" que "ditou" e que escreveu pode ser compreendida como mais uma palavra alinhada às racionalidades e verdades nas quais estava profundamente imerso.

Contudo, a reflexão aqui desenvolvida não consegue recobrir plenamente aquilo que se processa no ordinário das aulas, tampouco o que se processa no extraordinário jogo da recepção. O que efetivamente se deu nas aulas "ditadas" pelo médico baiano durante os três anos em que ministrou a disciplina de história da educação? Que efeitos individuais e de conjunto as aulas e o livro produziram nas jovens estudantes? Com a morte do Peixoto e a substituição do livro na Coleção "Atualidades Pedagógicas", o que se construiu em regular e novidade? Que novos começos se tentaram fabricar e que tradições se procurou manter nos projetos de formação e no domínio mais particular da disciplina?

Este inquérito remete e exige outro tipo de operação, não contemplada no presente estudo. No entanto, são efetivamente estas as questões, que ainda marcam o nosso presente, que deram sentido e orientaram o trabalho com a documentação explorada, isto é, um livro destinado exclusivamente à formação de professores, considerado o primeiro manual com estas características e, ao mesmo tempo, os registros de aula elaborados por um médico-professor que lhe serviu de guia e de balizador para as aulas que conduziu entre os anos de 1932 e 1934 no Instituto de Educação do Rio de Janeiro. Certamente, não encontramos "a pátria primeira", no sentido de se pensar a origem da disciplina e do ensino de história da educação.

O prometido mundo civilizado a ser construído com base na ciência ainda se constitui em desafio aberto, visível nas inúmeras desigualdades, algumas delas amparada em processos de racionalização cada vez mais refinados. O possível de ser observado na sociedade, nas escolas e na formação de professores são as várias (des)continuidades que atravessam e regulam o nosso presente de maneiras muito diversas; indício de que as lições do passado na forma de noções de história da educação seguem itinerários inesperados, surpreendentes; incontroláveis e imprevisíveis. Por vezes, inapetentes e fatigantes.

\section{Referências}

DUGANN, Stephen Pierce H. A student textbook in the History of Education. New York/Chicago: D. Appleton and Company, 1916.

FOUCAULT, Michel. "Nietzsche, a genealogia e a história." In: FOUCAULT, Michel. Microfísica do poder. Tradução: Roberto Machado. 10a ed. Rio de Janeiro: Graal, 1992.

GONDRA, José. G. Abílio Cesar Borges. In: FAVERO, Maria de Lourdes; BRITO, Jader. Dicionário dos Educadores no Brasil - da Colônia aos dias atuais. Rio de Janeiro: Editora da UFRJ, 2002. 
GONDRA, José; ASCOLANI, A. Pela classe, pelo livro: a fundação de uma História da Educação para professores, no Brasil e na Argentina. In: VIDAL, Diana.; ASCOLANI, Adrián. (Org.). Reformas educativas no Brasil e Argentina. São Paulo: Cortez, 2009.

GONDRA, José; TEIXEIRA, Giselle Baptista. Observatório das aulas? Livros escolares e pesquisa em história da educação. In: Ana Waleska Mendonça. (Org.). História e Educação Dialogando com as fontes. Rio de Janeiro: Editora Forma \& Ação, 2010.

GONDRA, José G. Temperar a alma, retemperar os músculos: corpo e História da Educação em Afranio Peixoto. Pro-Posições, Campinas, v.22, n.3, p.19-34, 2011. http://dx.doi.org/10.1590/S0103-73072011000300003

GONDRA, José; SILVA, José Cláudio S. Escritas da história - um estudo da produção de Afranio Peixoto. In: GONDRA, José; SILVA, José Cláudio. História da Educação na América Latina: ensinar \& escrever. Rio de Janeiro: EdUERJ, 2011.

GONDRA, José G.; SILVA, José C. Sooma. Textbooks in the history of education: notas para pensar as narrativas de Paul Monroe, Stephen Duggan e Afranio Peixoto. Revista Brasileira de Estudos Pedagógicos, v. 92, p. 702-722, 2011a.

GONDRA, José G.; SILY, Paulo R. M. Narrativas da História e Representações do Estado: Um estudo do caso Stephen Duggan (1870-1950). Teias, v. 28, p. 1-17, 2012.

GONDRA, José G.; SILY, Paulo R. M. Narrativas em Trânsito: Apontamentos sobre internacionalização da história e historiografia da educação nas Américas (1916-1934). Revista

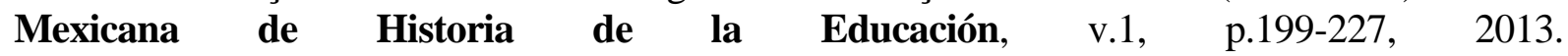
https://doi.org/10.29351/rmhe.v1i2.24

HOFSTETTER, Rita. Matrizes do internacionalismo educativo à era de sua primeira institucionalização em uma escala global: o exemplo do bureau internacional de educação no entreguerras. In GONDRA, José; SIMÕES, Regina Helena; MACHADO, Maria C. G. (Orgs.). História da Educação, matrizes interpretativas e internacionalização. Vitória: EDUFES, 2017.

MEDINA, José. Toward a Foucaultian Epistemology of Resistance: Counter-Memory, Epistemic Friction, and Guerrilla Pluralism. Foucault Studies, No. 12, pp. 9-35, October, 2011. https://doi.org/10.22439/fs.v0i12.3335

MIGNOT, Ana C. V. Baú de memórias, bastidores da história: legado de Armanda Alvaro Alberto. Bragança Paulista, EDUSF, 2002.

MONARCHA, Carlos; LOURENÇO FILHO, Ruy (orgs). Por Lourenço Filho: uma bioblibliografia. Brasília: Instituto Nacional de Estudos e Pesquisas Educacionais, 2001. Disponível em http://portal.inep.gov.br/documents/186968/484703/Por+Louren\%C3\%A7o+ Filho+uma+bibibliografia/f0480a5b-3b43-43a3-b491-f7fedd3eca0c?version=1.5. Acesso em 1 de fevereiro de 2019.

MONROE, Paul. A brief-course in the history of education. New York: Macmillan, c1907.

MONROE, Paul. História da educação. Tradução de Nelson Cunha de Azevedo. 1. ed. São Paulo: Companhia Editora Nacional, 1939. 
MORAES, José D. Armanda Álvaro Alberto: Pensamento e ação nos anos 1930. Anais do IV CBHE, 2006. Disponível em http://www.sbhe.org.br/novo/congressos/cbhe4/individuaiscoautorais/eixo06/Jose\%20Damiro\%20de\%20Moraes\%20-\%20Texto.pdf. Acesso em 1 de fevereiro de 2019.

PEIXOTO, Afrânio. Noções de História da Educação. São Paulo: Cia. Editora Nacional, 1933.

PEIXOTO, Afrânio. Noções de História da Educação. 2 ${ }^{a}$. ed. São Paulo: Cia. Editora Nacional, 1936.

PEIXOTO, Afrânio. Noções de História da Educação. $3^{\text {a }}$. ed. São Paulo: Cia. Editora Nacional, 1942.

PINHEIRO, Fernanda; SILY, Paulo \& GONDRA, José. A natureza por princípio e a ciência como meio: apropriações de Herbert Spencer no eixo luso-brasileiro (1861-1886), 2019 (no prelo).

RESENDE, Haroldo. A história na perspectiva genealógica de Michel Foucault. ANPUH XXIII Simpósio Nacional de História. Londrina, 2005.

RIBEIRO, Leonídio. Afranio Peixoto. Rio de Janeiro: Edições Conde, 1950.

ROTHBARD, Murray. Educação: livre e obrigatória. São Paulo: Instituto Ludwig von Mises, 2013.

SILVA, José Cláudio Sooma; FAVARO, Marta Regina Gimenez. Paul Monroe e a circulação de uma modalidade narrativa para se pensar e ensinar as histórias da educação. Revista Brasileira de História da Educação, Maringá-PR, v. 14, n. 3 (36), p. 181-204, set./dez. 2014. http://dx.doi.org/10.4025/rbhe.v14i3.574.1

SOBE, Noah. Fontes, teoria, escolarização e infância: afeto e corporeidade nas escolas progressistas norteamericanas do amanhã. In: GONDRA, José; SIMÕES, Regina Helena; MACHADO, Maria C. G. (Orgs.). História da Educação, matrizes interpretativas e internacionalização. Vitória: EDUFES, 2017.

TAMBIAH, Stanley. Múltiplos ordenamentos de realidade: o debate iniciado por Lévy-Bruhl

Cadernos de campo, São Paulo, n. 22, p. 1-384, 2013. Disponível em www.revistas.usp.br/cadernosdecampo/article/download/52613/pdf 5/. Acesso em 4 de fevereiro de 2019.

TAMBOUKOU, Maria. Writing Genealogies: an exploration of Foucault's strategies for doing research. Discourse: Studies in the Cultural Politics of Education, 20:2, 201-217, 1999.

VIEIRA, Carlos Eduardo. A escrita da História da Educação no Brasil: formando professores através de noções de história. In: GONDRA, José; SILVA; José Cláudio. História da Educação na América Latina: ensinar \& escrever. Rio de Janeiro: EdUERJ, 2011. 